$15^{\text {th }}$ International Conference on

AEROSPACE SCIENCES \& AVIATION TECHNOLOGY,

ASAT - 15 - May 28 - 30, 2013, Email: asat@mtc.edu.eg,

Military Technical College, Kobry Elkobbah, Cairo, Egypt,

Tel: +(202) $24025292-24036138$, Fax: +(202) 22621908

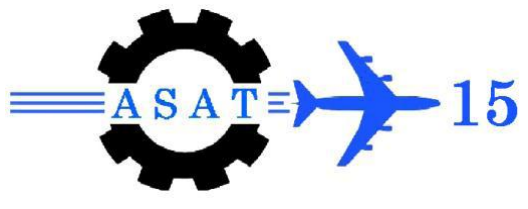

\title{
Fabrication of Hybrid Aluminum Matrix Composite by Directly Oxidized and Pressureless Infiltration Technique
}

\author{
Bakr M. Rabeeh*
}

\begin{abstract}
The oxidation behavior of Al-Si-Mg alloy along with the addition of boric acid particles in the temperature range from $1000^{\circ} \mathrm{C}$ to $1200^{\circ} \mathrm{C}$ was investigated for aerospace applications. Directly oxidized aluminum with the effect of alloying elements introduced with nontraditional infiltration technique produce both borosilicate particulates and/or fiber structure of reinforced aluminum matrix composite. Two different fabrication processes are utilized either by change of composite constituents weight fraction, or by the fixation weight fraction along with pressureless infiltration technique. Two different approaches introduced for new nontraditional hybrid aluminum matrix composites. The dependence of reinforcement weight fraction on direct oxidation time and the addition of alloying elements is controlled by pressureless infiltration process. Using recycled aluminum alloy, aluminum alloy containing $\mathrm{Si}$ and $\mathrm{Mg}$ as matrix induce the synthesis of either particulates and/or fiber in residual aluminum matrix. Boric acid added at $5 \%$ weight fractions either with DIMOX or with DIMOX and infiltration technique. The obtained results analyzed utilizing optical microscopy, scanning electron microscopy with energy dispersive X-ray spectroscopy, in addition to mechanical characterization. The control of composite ingredients shape, size and uniformity is obtained via nontraditional pressureless infiltration technique. Besides, bulk and Nano borosilicate and carbon fibers are also intrinsically introduced.
\end{abstract}

Keywords: direct oxidation DIMOX; extrinsic; intrinsic modification, interfacial reaction; pressureless infiltration.

\section{Introduction}

A composite material is a 'material system' composed of a combination of two or more micro or macro constituents that differ in form, chemical composition and which are essentially insoluble in each other. Aluminum-matrix composites are not a single material but a family of materials whose stiffness, strength, density, thermal and electrical properties can be tailored. The matrix alloy, reinforcement material, volume and shape of the reinforcement, location of the reinforcement and fabrication method can all be varied to achieve required properties. The aim involved in designing metal matrix composite materials is to combine the desirable attributes of metals and ceramics. One of the major challenges when processing MMCs is achieving a homogeneous distribution of reinforcement in the matrix as it has a strong impact on the properties and the quality of the material [1].

Professor, Faculty of Engineering and Materials Science, German University in Cairo, GUC. brabeeh@hotmail.com. 
To obtain a specific mechanical/physical property, ideally, the MMC should consist of fine fibers/whiskers distributed uniformly in a ductile matrix and with clean interfaces between ingredients and matrix. MMCs are generally processed with solid state processing (hot unidirectional pressing and hot isostatic pressing), and liquid metal routes (stir casting and infiltration). However, A direct metal oxidation, DIMOX, route is also used for specific applications[2].This work aimed at the application of DIMOX along with infiltration technique for the synthesis and processing of aluminum metal matrix composite reinforced with both whiskers/particulates and fibers in a nontraditional hybrid materials for aerospace applications. One of the problems associated with the infiltration route is the high volume fraction of the reinforcement which requires additional processes to dilute the content to the required levels. Prolonged processing times and increased processing steps at elevated temperatures aid the chemical reactions between matrix and reinforcements, which often result in brittle secondary phases [3]. Metal matrix composites (MMCs) are one of the important innovations in the development of advanced materials.

Among the various matrix materials available, aluminum and its alloys are widely used in the fabrication of MMCs and have reached the industrial production stage. The emphasis has been given on developing affordable Al-based MMCs with various hard and soft reinforcements ( $\mathrm{SiC}, \mathrm{Al}_{2} \mathrm{O}_{3}$, borosilicate, and others delocalized zone of interests) because of the likely possibilities of these combinations in forming highly desirable composites [4]. Borate glass, in the form of fibers or particulates, has long been recognized as a high-strength, low-density material. Aluminum borosilicate fibers/particulate MMCs produced by solidification techniques represent a class of inexpensive tailor-made materials for a variety of engineering applications such as aerospace components [5], bushes, and bearings [6]. Their uses are being explored in view of their superior technological properties such as the low coefficient of friction [7], low wear rate [8], superior gall resistance [3] and high thermal limitations [9].This has led to increases research interest on evaluating the effect of type and weight fraction of reinforcement in the matrix and procedure that used to produce of MMCs [9-13]. In this investigation varying volume fractions of boric acid are added to the recycled 6xxx aluminum alloy to state the solubility limit and the kinetic of boric acid addition to the DIMOX aluminum. The addition of infiltration technique to the DIMOX sample is introduced with remarkable results. The control of reinforcements shape and size along with its uniformity are obtained. Constituents' agglomeration as well as its non-uniformity is achieved via infiltration. New carbon rich borosilicate fiber in bulk and Nano scale is achieved.

\section{Materials and Methods}

\section{Materials}

The matrix material used in the experimental investigation was an aluminum alloy ( $\mathrm{Si}-$ $8.54 \%, \mathrm{Mg}-1.13 \%$ ), whose chemical composition is listed in Table 1.

Table 1 Chemical composition (wt. \%) of the Al-alloy used in the study

\begin{tabular}{c|c|c|c|c|c|c|c|c|c|c}
\hline \hline $\mathrm{Cu}$ & $\mathrm{Mg}$ & $\mathrm{Si}$ & $\mathrm{Fe}$ & $\mathrm{Mn}$ & $\mathrm{Ni}$ & $\mathrm{Zn}$ & $\mathrm{Pb}$ & $\mathrm{Sn}$ & $\mathrm{Ti}$ & $\mathrm{Al}$ \\
\hline 3.37 & 1.13 & 8.54 & 1.20 & 0.19 & 0.04 & 1.36 & 0.07 & 0.03 & 0.04 & Balance \\
\hline \hline
\end{tabular}


This alloy is mainly used when good mechanical properties are required. It is, in practice, a general-purpose high strength casting alloy. In its heat-treated form, its tensile strength can be increased from around $130-150 \mathrm{~N} / \mathrm{mm}^{2}$ to up to $230-280 \mathrm{~N} / \mathrm{mm}^{2}$. Aluminum and silicon alloys have no solid solubility below the eutectic, and the microstructure solidifies in the form of silicon particles in an aluminum matrix. Aluminum-silicon castings have good corrosion resistance and are used in the cases where particularly high strength is required.

\section{Experimental Procedure}

The metal matrix composite used in the present work was carried out either by the direct metal oxidation method, DIMOX, or DIMOX with infiltration technique. The aluminum metal (scrap) was melted to the desired DIMOX temperature of $1150^{\circ} \mathrm{C}$ in alumina crucibles with addition of $5 \mathrm{wt}$. \% boric acid. The melt was hold in the furnace for a prescribed holding time of 20 minutes. A three-phase electrical resistance furnace with temperature controlling device was used for melting. For each melting $300-400 \mathrm{~g}$ of alloy was used. The DIMOX molten metal was then poured in a metallic mold. For the purpose of comparison, the DIMOX samples were applied to non-traditional infiltration technique. The DIMOX samples, with 5 wt. \% boric acid additions, were then dipped in molten boric acid at temperatures of $550^{\circ} \mathrm{C}$ separately for 20 minutes holding time. The melting was carried in a tilting electric furnace in a range of $1150 \pm 10^{\circ} \mathrm{C}$.

\section{Results and Discussions}

\section{Macro-and micro structural characterization}

Macro structural studies were conducted in order to investigate the distribution of composite constituents intrinsically retained in the residual aluminum metal matrix. Samples were taken to reveal the particle distribution on a macroscopic scale at fracture surface. Micro structural characterization studies were conducted on unreinforced as well as on reinforced samples. This was accomplished by using optical microscope. The composite samples were metallographically polished prior to examination. Characterization was done in etched conditions. Figure 1 to 3 present macrostructure characterizations of the DIMOX samples without addition and with the addition of $5 \%$ boric acid compared to that with DIMOX and infiltration technique respectively ( $5 \%$ boric acid). Composite constituents more dominant at Figure 2, however with agglomeration and delocalized coarse whiskers and nonuniformity of reinforcements. Figure 3 presents the uniformity of composite constituents along fracture surface that conducted with DIMOX and infiltration technique.

\section{Microstructure Examination}

Metallographic samples were sectioned from the cast bars. A $0.5 \%$ HF solution was used to etch the samples wherever required. To see the difference in distribution of fiber/whiskers in the aluminum matrix microstructure of samples; first group of sample was prepared with DIMOX with 5 wt. \% boric acid addition, and the second group of sample has been fabricated with the addition of infiltration technique just after DIMOX. The two groups were developed via the recycling of aluminum alloy, Al-Si-Mg scrap. The objective of this work is to monitor the effect of infiltration technique as a new nontraditional process that induces fibrous or whiskers structure reinforced aluminum alloy. Agglomeration and non-uniformity of composite constituents were dominant when applying DIMOX. Figure 4 presents scanning electron microscopy of DIMOX sample at $1150^{\circ} \mathrm{C}$ and $5 \%$ boric acid with delocalized bulk 
whiskers agglomeration at sample center. Non-uniformity and delocalized composite ingredients were obtained as massive whiskers $(5-350 \mu \mathrm{m})$. Figure 5 presents scanning electron microscopy of DIMOX sample at $1150^{\circ} \mathrm{C}$ and $5 \%$ boric acid with delocalized bulk randomly distributed fibers at sample surface (low mag.). Three different composite constituents were monitored at the surface of the sample as; short fibers (A), particulates (B) and bulk whiskers (C) and presented in Figure 6. Faceted structure is the character of grain boundaries as well as bulk whiskers that presented at Figure 7 and Figure 8 for high magnification. Energy dispersive X-ray spectroscopy is conducted at the three different composite constituents A, B and C and presented in Figure 9 to Figure 11 respectively. The EDX analysis is summarized by Chemical composition of delocalized zone of interests, fiber (A), particulates (B), and bulk whiskers (C) and presented in Table 2. The DIMOX structure with boric acid addition introduced with non-uniformity of composite structure along its central axis. The segregation of alloying elements induces hybrid composite structure with different composite ingredients.

Figure 12 to Figure 18 present the obtained scanning electron microscopy and EDX for the second group of samples that DIMOX with infiltration pressureless technique. Figure 12 and Figure 13 presents scanning electron microscopy of DIMOX sample at $1150^{\circ} \mathrm{C}$ and $5 \%$ boric acid and infiltration at $550^{\circ} \mathrm{C}$, with uniformly distributed surface ingredients at low mag. and high mag. respectively. New hybrid composite morphology is obtained with fibrous/whiskers uniformly distributed in a close simulation of Widmanstatun structure. Figure 14 presents scanning electron microscopy of DIMOX sample at $1150^{\circ} \mathrm{C}$ and $5 \%$ boric acid and infiltration at $550^{\circ} \mathrm{C}$, with minor coating and loose fiber (at sample center) with low magnification. The outer surface of the sample reveals bulk fibers that presented in Figure 12 and 13. However Figure 14 and Figure 15 present two different types of fibrous structure $\sim 10$ $\mu \mathrm{m}$ and $\sim 1 \mu \mathrm{m}$ fiber diameter thickness. EDX is conducted to resolve the three types of fibrous structure those being obtained and analyzed at Figure 16, 17 and 18for dispersed fiber, embedded fiber and coating fiber respectively. The final chemical compositions of the three type of fiber are being concluded in table 3. Borosilicate fibers in a bulk as well as in Nano scale are introduced as coating as well as dispersed fibers. Boron content is dominant at the three types of delocalized fibers that are recommended for aerospace applications as well as in biomedical engineering applications.

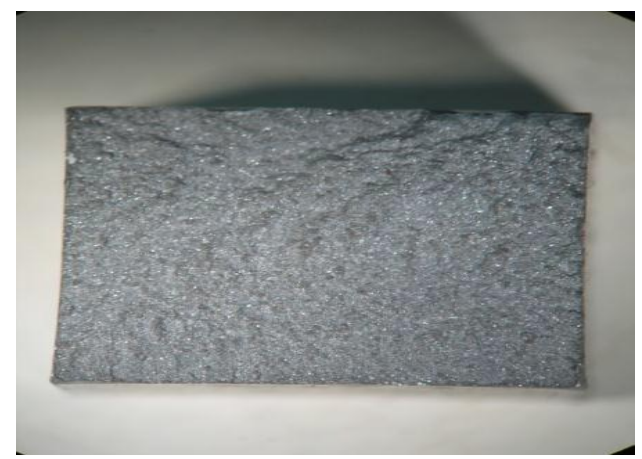

Fig. 1 Macrostructure examination of DIMOX sample at $1150^{\circ} \mathrm{C}$ for 20 minutes. 


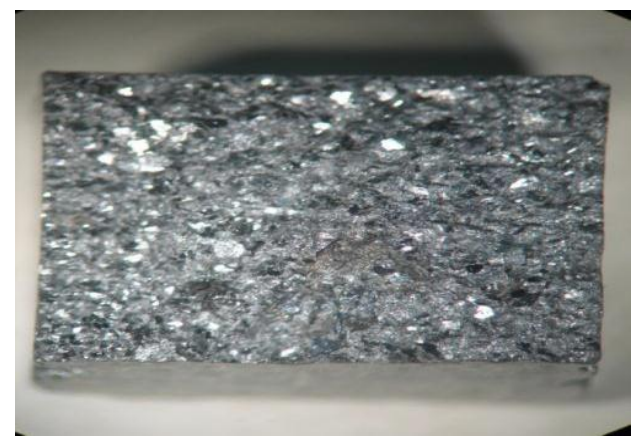

Fig. 2 Macrostructure examination of DIMOX sample at $1150^{\circ} \mathrm{C}$ for 20 minuteswith $5 \%$ boric acid addition.

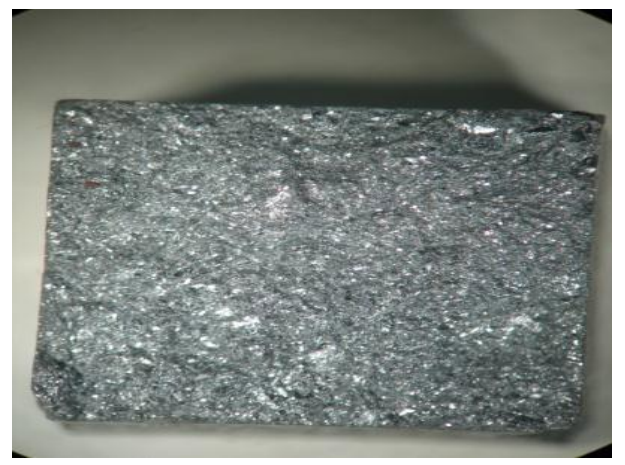

Fig. 3 Macrostructure examination of DIMOX sample at $1150^{\circ} \mathrm{C}$ for 20 minutes with $5 \%$ boric acid addition with infiltration technique.

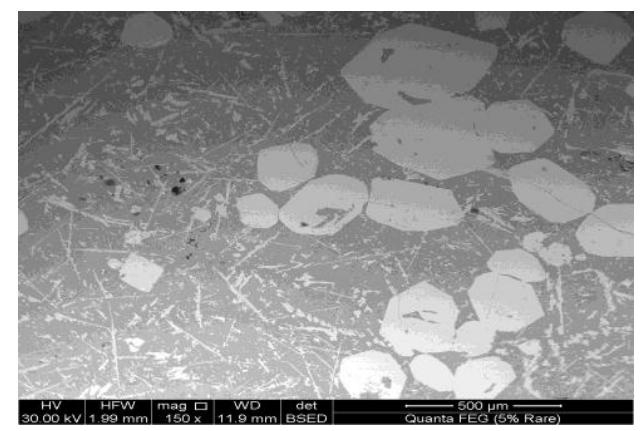

Fig. 4 Scanning electron microscopy of DIMOX sample at $1150^{\circ} \mathrm{C}$ and $5 \%$ boric acid with delocalized bulk whiskers agglomeration at sample center [low mag.]

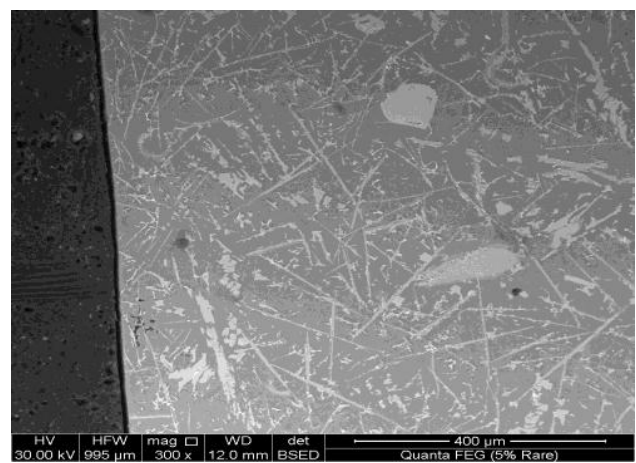

Fig. 5 SEM of DIMOX sample at $1150^{\circ} \mathrm{C}$ and $5 \%$ boric acid with delocalized bulk randomly distributed fibers at sample surface [low mag.] 


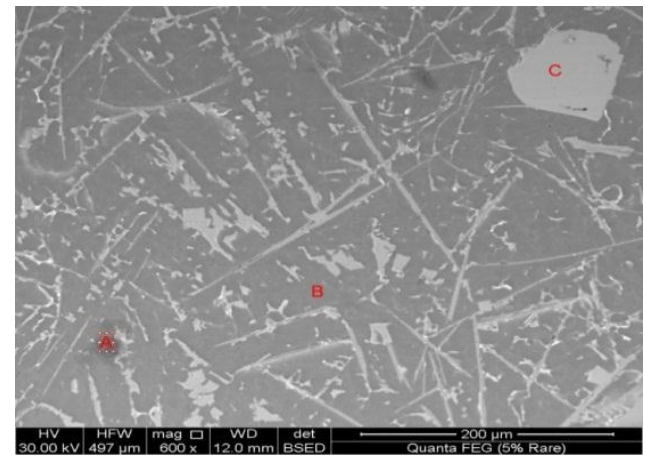

Fig. 6 SEM of DIMOX sample at $1150^{\circ} \mathrm{C}$ with $5 \%$ boric acid and three marked zones for EDX: a) fiber, b) particulate and c) whisker [high mag.]

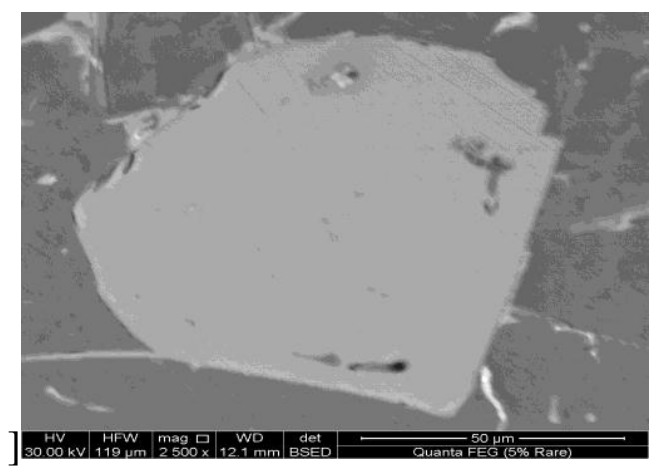

Fig. 7 SEM of DIMOX sample at $1150^{\circ} \mathrm{C}$ with $5 \%$ boric acid and bulk whisker [low mag.]

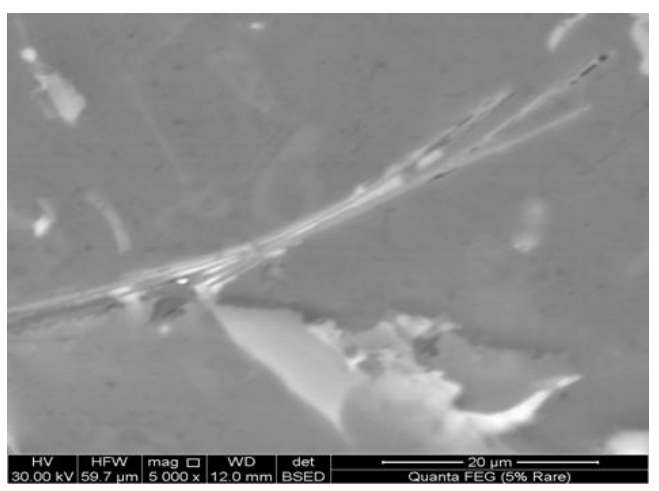

Fig. 8 SEM of DIMOX sample at $1150^{\circ} \mathrm{C}$ with $5 \%$ boric acid and bulk whisker twining [high mag.]

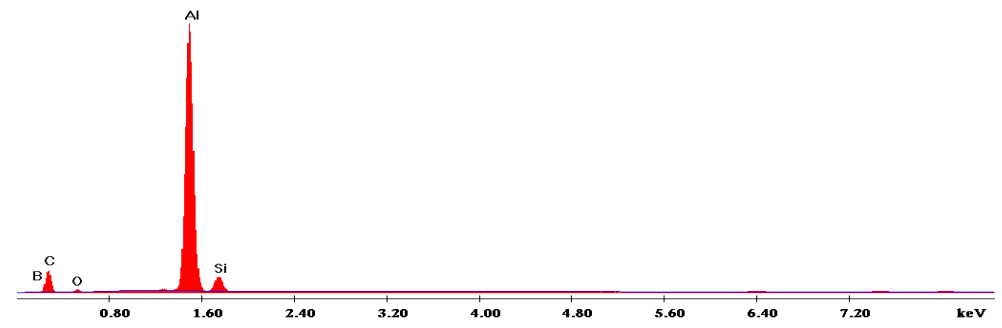

Fig. 9 Energy dispersive x-ray spectroscopy of marked A zone [fiber structure, Fig. 6] 


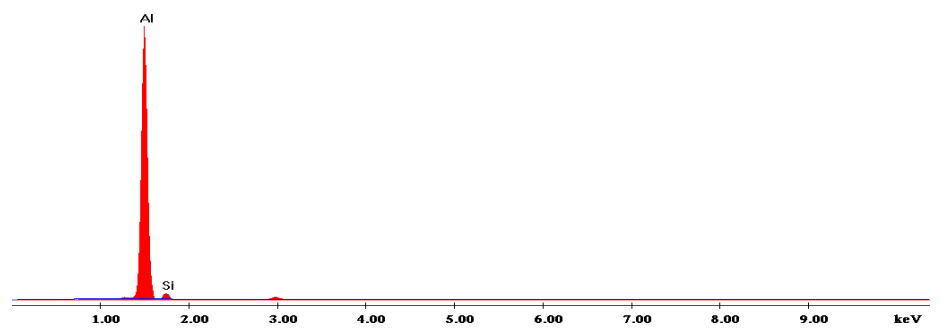

Fig.10 Energy dispersive x-ray spectroscopy of marked B zone [particulate structure, Fig. 6]

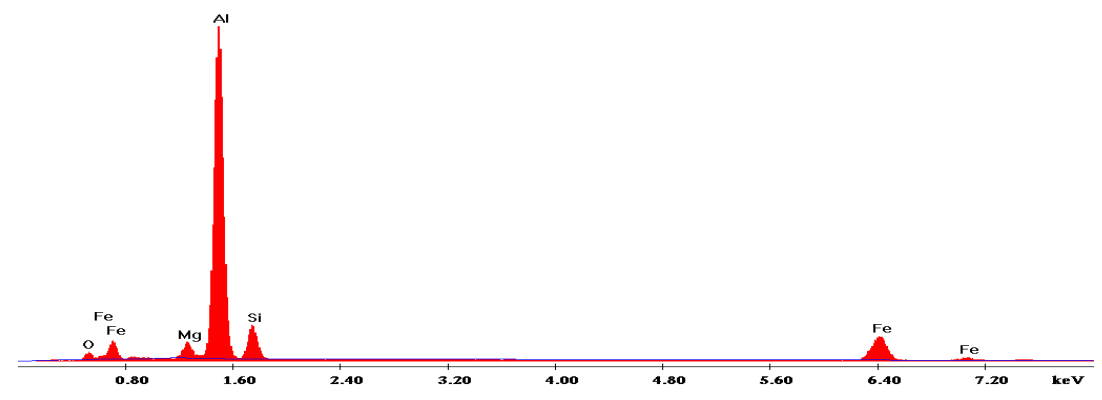

Fig.11 Energy dispersive x-ray spectroscopy of marked C zone [bulk whisker structure]

Table 2 Chemical composition of delocalized zone of interests, fiber (A), particulates (B), and bulk whiskers (C)

\begin{tabular}{c|c|c|c}
\hline \hline \multirow{2}{*}{ Element } & Zone A & Zone B & Zone C \\
\cline { 2 - 4 } & \multicolumn{3}{|c}{ Wt. \% } \\
\hline $\mathrm{B}$ & 0.75 & - & - \\
\hline $\mathrm{C}$ & 49.51 & - & - \\
\hline $\mathrm{O}$ & 3.81 & - & 3.15 \\
\hline $\mathrm{Mg}$ & - & - & 2.88 \\
\hline $\mathrm{Al}$ & 40.80 & 90.37 & 61.51 \\
\hline $\mathrm{Si}$ & 5.13 & 9.63 & 11.21 \\
\hline $\mathrm{Fe}$ & - & - & 21.25 \\
\hline Total & 100 & 100 & 100 \\
\hline \hline
\end{tabular}

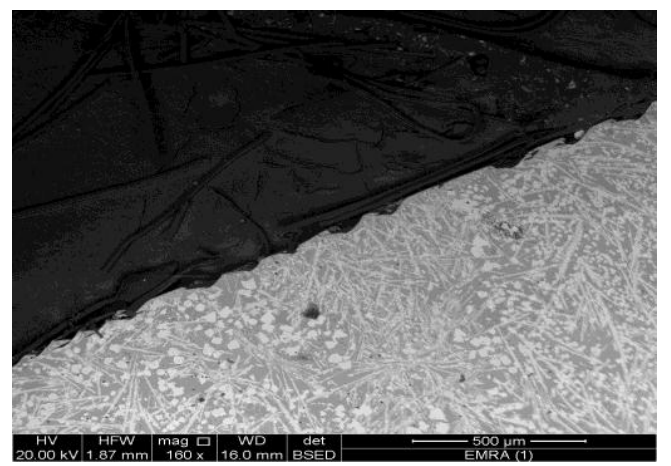

Fig.12 Scanning electron microscopy of DIMOX sample at $1150^{\circ} \mathrm{C}$ and $5 \%$ boric acid and infiltration at $550^{\circ} \mathrm{C}$, with uniformly distributed ingredients [low mag.] 


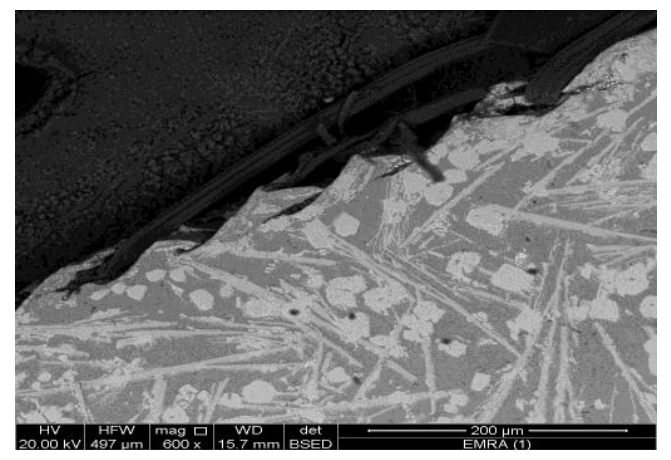

Fig.13 Scanning electron microscopy of DIMOX sample at $1150^{\circ} \mathrm{C}$ and $5 \%$ boric acid and infiltration at $550^{\circ} \mathrm{C}$, with uniformly distributed ingredients and coating layer [high mag.]

Fig.14 Scanning electron microscopy of DIMOX sample at $1150^{\circ} \mathrm{C}$ and $5 \%$ boric acid and infiltration at $550^{\circ} \mathrm{C}$, with minor coating fiber [high mag.]

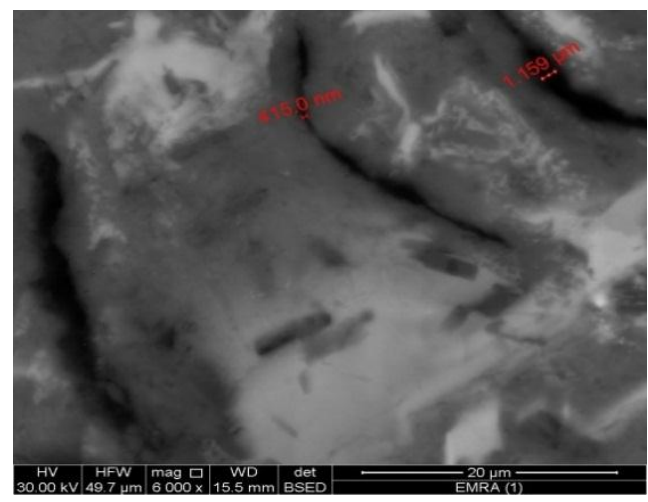

Fig.15 Scanning electron microscopy of embedded fibers and bulk fibers [v. high mag.]

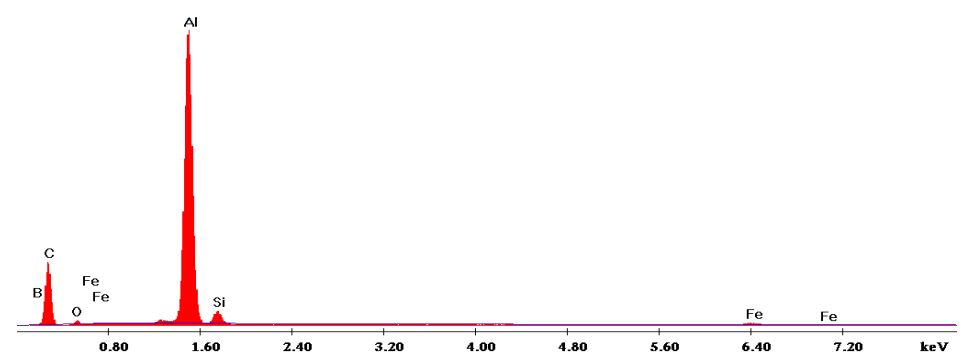

Fig. 16 EDX of a sample DIMOX and infiltration technique a dispersed fibrous structure. 


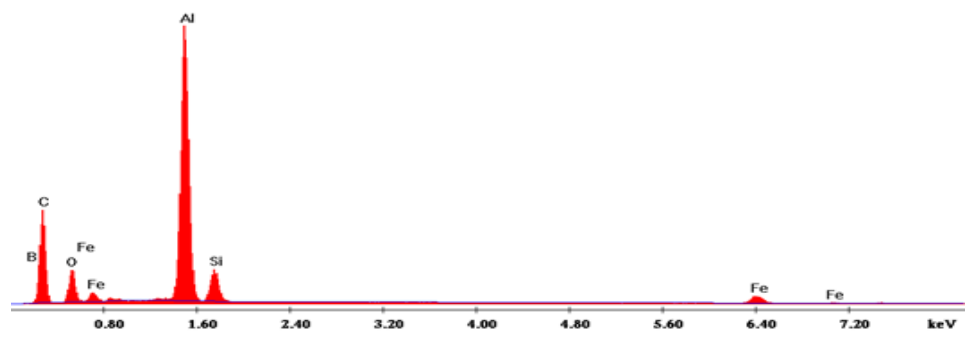

Fig.17 EDX of a sample DIMOX and infiltration technique embedded fibrous structure.

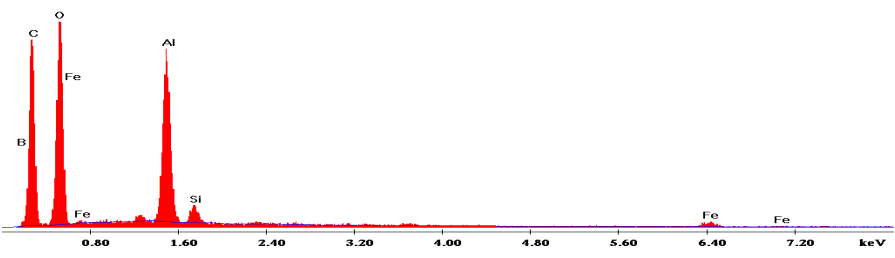

Fig.18 EDX of a sample DIMOX and infiltration technique coated fibrous structure.

Table 3 Chemical composition of delocalized zone of interests, dispersed fiber (A), embedded fiber (B), and coating fiber (C)

\begin{tabular}{c|c|c|c}
\hline \hline \multirow{2}{*}{ Element } & Dispersed fiber A & Embedded fiber B & Coating fiber C \\
\cline { 2 - 4 } & & Wt. \% \\
\hline $\mathrm{B}$ & 00.74 & 01.37 & 04.07 \\
\hline $\mathrm{C}$ & 54.64 & 51.50 & 45.22 \\
\hline $\mathrm{O}$ & 02.01 & 12.05 & 37.04 \\
\hline $\mathrm{Mg}$ & - & - & - \\
\hline $\mathrm{Al}$ & 38.01 & 26.68 & 01.86 \\
\hline $\mathrm{Si}$ & 02.57 & 04.21 & 01.58 \\
\hline $\mathrm{Fe}$ & 02.03 & 04.20 & 100.00 \\
\hline Total & 100 & 100 &
\end{tabular}

\section{Conclusions}

DIMOX with the addition of boric acid is introduced with new nontraditional hybrid composite structure with fibrous and particulates. The non-uniformity and agglomeration of composite constituents is dominant along surface and through sample center. The wettability of composite constituents that intrinsically produced along with alloy segregation has a synergetic effect of composite processing. The addition of infiltration technique directly after DIMOX at $550^{\circ} \mathrm{C}$ for 20 minutes holding time introduced with its structural effect. The control of ingredients shape and size and its delocalized zone is introduced with new nontraditional hybrid composite structure. The refinements of fibrous/whiskers with its uniformity is introduced with the control of boron contents along three types of fibers. Dispersed, embedded and coating fibers are three different fibers obtained via infiltration technique. Infiltration technique is being considered as a semisolid reaction, rheocasting, that has a tremendous effect on sample coating, increase the solubility limit of boric acid that induce a nontraditional borosilicate fibrous structure. The agglomeration and nonuniformity of composite constituents are being controlled via infiltration technique. Borosilicate richcarbon fibers are introduced as coating and intrinsically mechanically alloyed in a hybrid composite structure. 


\section{References}

[1] Mares M.," Some issues on tailoring possibilitiesfor mechanical properties of particulate reinforcedmetal matrix composites", Journal of Optoelectronicsand Advanced Materials. 3(1): 19-124.2001.

[2] T.W. Clyne and P.J. Withers." An Introductionto Metal Matrix Composites", 1st Ed., CambridgeUniversity Press, Cambridge. pp. 1-10.1993.

[3] Rajnesh T." Synthesis and tribologicalcharacterization of in-situ cast Al-TiC composites",Journal of Wear. 259. pp. 569-576.2005.

[4] Llyod D.J., Lagace H., Mcleod A. and Morris P.L. "Micro structural aspects of aluminum siliconcarbide particulate composites produced by a castingmethod", Materials Science and Engineering. 107: 73-80.1989.

[5] Hashim J., Looney L. and Hashmi M.S.J. "Thewettability of SiC particles by molten aluminum alloy", Journal of Materials Processing Technology. 119(1-3):324-328.2001.

[6] O.P. Modi, A.H. Yegneswaran, R. Asthana and P.K.Rohatgi. "Thermo mechanical Processing of Aluminum-based Particulate Composites”, J. Mater.Sci. 23(1): 83-92.1998.

[7] N. Eustathopoulos, J.C. Joud, P. Desre and J.M.Hicter. "The Wetting of Carbon by Aluminumand Aluminum Alloys", J. Mater. Sci. 9(8): 1233-1242.1974.

[8] Naher S., Brabazon D. and Looney L. "Development and assessment of a new quick quenchstir caster design for the production of metal matrixcomposites", Journal of Material ProcessingTechnology. 166: 430-439.2004.

[9] Dunia Abdul Saheb, "Aluminum Silicon Carbide and Aluminum Graphite Particulate Composites", ARPN Journal of Engineering and Applied Sciences, Vol. 6, No. 10, October 2011.

[10] D.M. Skibo, D.M. Schuster and L. Jolla. "Process for preparation of composite materialscontaining nonmetallic particles in a metallic matrixand composite materials" US Patent No. 4-786-467.1988.

[11] Balasivanandha S., Kaarunamoorthy L., Kaithiresan S.and Mohan B. "Influence of stirring speed and stirring time on distribution of particles in cast metalmatrix composite", Journal of Material ProcessingTechnology. 171: 268-273.2006.

[12] Wannasin J. "Fabrication of metal matrixcomposites by a high- pressure".2005.

[13] S. M. Suresh, Debadutta Mishra, A. Srinivasan, R. M. Arunachalam3 and R. Sasikumar, "Production and Characterization of Micro and nano A12O3 Article-Reinforced Lm25 AluminumAlloy Composites", ARPN Journal of Engineering and Applied Sciences, Vol. 6, No. 6, June 2011. 